\title{
2
}

УДК 159.91

\section{УЧЕНИЕ С. Н. ШПИЛЬРЕЙН О ДЕСТРУКЦИИ: ТЕОРЕТИЧЕСКИЕ И ПСИХОБИОГРАФИЧЕСКИЕ АСПЕКТЫ}

\section{Филатов Филипn Робертович}

В статье приводится характеристика чентральной работы в научном наследии С. Н. Шпильрейн - «Деструкция как причина становления» (1912). Эта классическая работа одного из пионеров психоанализа рассматривается как научная альтернатива концепции 3. Фрейда о влечении к смерти. 3. Фрейд определял влечение к смерти как регресс, «стремление к восстановлению какого-либо прежнего состояния» или «тенденцию возврата к неорганическому состоянию», «к покою неживой материи». Это вполне соответствует его идее о «консервативной природе Либидо». Согласно С. Н. Шпильрейн, деструкция предполагает уничтожение прежнего состояния ради возникновения нового, разрушение, обеспечивающее трансформацию, «воскрешение» индивида в новой форме.

С. Шпильрейн предлагает различать два основных инстинкта: инстинкт самосохранения и инстинкт сохранения вида. Первый из них прост по структуре и консервативен, т. к. направлен на сохранение индивида в уже имеющемся наличном состоянии. Второй преследует цель сохранения рода путем постоянных изменений и новообразований, независимо от эгоистических желаний индивида и его стремления к устойчивости. Инстинкт сохранения рода имеет сложную двухкомпонентную структуру; эротическое влечение неотделимо в нем от деструкции. Таким образом, этот инстинкт амбивалентен по своей природе и включает в себя как отрицательные, так и положительные (с точки зрения Эго) компоненты.

Идеи С. Н. Шпильрейн о деструкиии анализируются в контексте деструктивных событий ее жизни. В статье прослеживаются этапы жизни С. Н. Шпильрейн, обсуждается ее вклад в становление психоанализа. Автор анализирует кониепцию деструкции С. Н. Шпильрейн как оригинальную попытку интегрировать идеи К. Г. Юнга и 3. Фрейда на новой теоретической основе.

Ключевые слова: Сабина Шпильрейн, Карл Юнг, Ойген Блейлер, Зигмунд Фрейд, психоанализ, первичные влечения, либидо, принцип удовольствия, деструкция, влечение к смерти.

\section{Введение}

Эта статья посвящена примечательному образцу психоаналитического дискурса, в котором деструкция представлена как неотъемлемая составляющая 
природы человека и который сегодня прочитывается историографами словно бы в обрамлении деструктивных жизненных обстоятельств его автора - последовательницы К. Г. Юнга и 3. Фрейда, Сабины Николаевны Шпильрейн (1885-1942).

«Если ты долго смотришь в бездну, то бездна тоже всматривается в тебя», - афористично изрек Фридрих Ницше («По ту сторону добра и зла»), мыслитель, оказавший значительное влияние на научное творчество и мировоззрение Сабины Николаевны. Для прославленной ростовчанки деструкция стала не только предметом исследования, но и постоянной спутницей жизни. Это обстоятельство в свое время позволило академику В. И. Овчаренко заключить, что трагическая судьба первой русской женщины-психоаналитика прошла «под знаком деструкции» [3]. Следует добавить, что «бездна» сама выбрала свою выдающуюся исследовательницу задолго до того, как та осмелилась заглянуть в нее.

В посвященной ей литературе С. Н. Шпильрейн, как правило, предстает в трех ипостасях: как героиня запутанной и интригующей истории о чудесном исцелении с нежелательным побочным эффектом - влюбленностью в своего психоаналитика К. Г. Юнга [13]; как загадочная фигура «между Юнгом и Фрейдом», связавшая двух великих ученых мужей, невольно став первым поводом к их интенсивной и плодотворной переписке $[12,13,16,18]$; наконец, как автор собственного оригинального текста - темной и непонятой статьи о деструкции $[1,7,15,19,21]$. Замечательным результатом страданий и исканий первого периода ее творческой жизни стала опубликованная в 1912 г. и важнейшая для всей психоаналитической доктрины работа «Деструкция как причина становления» [20]. К сожалению, голос Шпильрейн-ученого по-прежнему заглушает доносящееся до нас эхо скандала, когда-то поднятого в психоаналитическом семействе, а ослепительное величие патриархов психоанализа не всегда позволяет увидеть в истинном свете и масштабе дарование их экстраординарной ученицы.

\section{Факты биографии С. Н. Шпильрейн}

Главный лейтмотив статьи Сабины Шпильрейн о деструкции, ее суть можно лаконично выразить следующим тезисом: феномен деструкции неразрывно связан с процессами трансформации и интеграции, происходящими на разных уровнях организации жизни [11]. Именно так, на наш взгляд, следует интерпретировать конструкт «причина становления». И в собственной судьбе Сабины Николаевны каждый новый виток биографической деструкции, вплоть до трагической гибели с дочерьми во время Холокоста в Змиевской балке (Ростов-на-Дону, август 1942), оборачивался попытками интеграции болезненного опыта, выводившими ее на новую ступень 
творческой самореализации (относительно жизненного пути С. Н. Шпильрейн, ее роли, характера заболевания и диагноза сложились различные точки зрения. Показательны в этом отношении две работы, в которых трактовки одних и тех же событий существенно расходятся: прославленная монография первооткрывателя С. Н. Шпильрейн Альдо Каротенуто и набирающая популярность в последние годы книга швейцарского психоаналитика Сабины Рихебехер [5, 16]. - Ф. Ф.). Так, попав вследствие душевного заболевания в клинику Бургхёльцли, она стала там же врачом и в конечном итоге психоаналитиком, а ее мучительная любовь к К. Юнгу поспособствовала написанию ряда выдающихся научных трудов.

Сабина Николаевна Шпильрейн - старшая дочь еврейского коммерсанта, энтомолога по образованию, выходца из Варшавы и впоследствии купца 1-ой гильдии Николая Аркадьевича Шпильрейна (1856-1938) и врачастоматолога Евы Марковны Шпильрейн, урожденной Люблинской (1863-1922). Родилась в Ростове-на-Дону 25 октября (7 ноября) 1885 г. Очень рано, уже в детские годы проявилась ее разносторонняя одаренность. Детский дневник Сабины Шпильрейн отражает многогранность ее интересов, раннее взросление, наблюдательность и проницательность, интерес к языку, склонность к рефлексии, психологическому анализу и словесному творчеству. Сабина была впечатлительной и ранимой девочкой с тонкой психической организацией, оригинальным складом ума и богатым воображением. У Николая и Евы Шпильрейн после Сабины родилось еще четверо детей: три ее младших брата - Ян (1887-1938), Исаак (1891-1938) и Эмиль (1899-1938), а также младшая сестра Эмилия (1895-1901), умершая от тифа в детском возрасте [5]. Братья Шпильрейн впоследствии также стали видными учеными и все трое были репрессированы по сфабрикованным обвинениям в разгар сталинских чисток.

К августу 1904 г., когда Сабина Шпильрейн оказывается вместе с матерью в Швейцарии и попадает в кантональную клинику Бургхёльцли, у девятнадцатилетней ростовской девушки обнаруживаются признаки нервнопсихического расстройства, которое вскоре будет диагностировано как истерия. Предпосылками этого заболевания стали, с одной стороны, патогенная атмосфера в семье, конфликты с родителями, чрезмерные требования, предъявляемые отцом семейства, жестокие наказания, а с другой стороны - внезапная смерть младшей сестры Эмилии, обернувшаяся для шестнадцатилетней Сабины глубокой душевной травмой $[2,4,5]$.

Николай Аркадьевич Шпильрейн был человеком деспотичным, неуравновешенным и неврастеничным. Стремясь дать детям основательное европейское образование, дабы во взрослой жизни они преуспевали и ни в чем не нуждались, он был склонен к крайностям. Нередко в обращении с детьми проявлял вспыльчивость и жестокость. В соответствии с его радикальными 


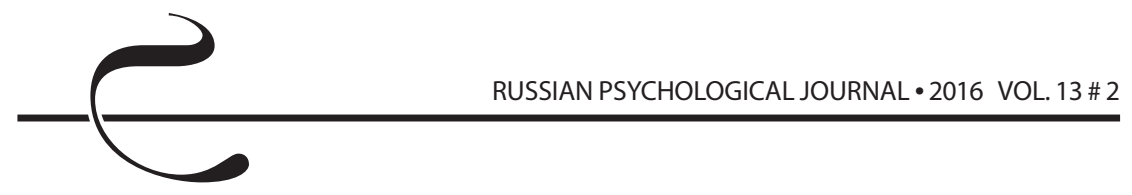

представлениями о воспитании, в семье в зависимости от дня недели говорили на разных языках: на немецком, французском, английском, причем уклонение от этой обязанности сурово каралось. Для старшей дочери отцовские наказания были невыносимы и вместе с тем носили выраженный сексуально окрашенный характер. Фактически, отец был в ее жизни первой фигурой, олицетворявшей не только на символическом, но и на физическом уровне глубинную взаимосвязь любви и деструкции. В ходе ассоциативного теста, проведенного с ней К. Юнгом, она призналась, что любит отца «с болью» [5].

Указанные обстоятельства и привели к тому, что психическое состояние Сабины Николаевны к 1904 г. стало крайне тяжелым и потребовало лечения. В этот год родители приняли судьбоносное решение отправить дочь за границу, в Швейцарию. Она поступила в клинику Бургхёльцли в Цюрихе вечером 17 августа 1904 г. Ее лечащим врачом был назначен молодой психиатр Карл Густав Юнг (1875-1961), уже тогда стремившийся внедрить новаторские психоаналитические идеи и методы 3. Фрейда в свою врачебную практику.

Результаты экспериментального применения аналитического подхода в лечении эксцентричной девушки из России превзошли все ожидания К. Юнга: меньше чем через год, 1 июня 1905 г. курс психоанализа был успешно завершен, а терапевтический эффект четко выражен и очевиден. К. Юнг расценил это как свою первую крупную победу и через некоторое время сообщил об успешном случае терапии в письме к 3. Фрейду.

Так открывается новая яркая страница биографии С. Н. Шпильрейн. В этот период начинается стремительный взлет вчерашней пациентки, приводившей в замешательство светила европейской психиатрии: обучение на медицинском факультете Цюрихского университета (1905-1909), специализация в области психиатрии, психоанализа и педологии, защита докторской диссертации под руководством К. Юнга и О. Блейлера (1911). Затем сотрудничество с 3. Фрейдом в Вене и, наконец, публикация новаторской статьи «Деструкция как причина становления» (1912), ставшей вехой в развитии психоаналитической теории $[10,11,20]$.

Все указанное поразительно как в контексте личной судьбы Сабины Шпильрейн, казалось бы, не сулившей ей ничего, кроме заточения в психиатрической клинике, так и в общем культурном контексте эпохи: фундаментальное образование и научное продвижение молодой еврейской женщины было редкостью не только для царской России, но и для просвещенной Европы.

\section{Учение С. Н. Шпильрейн о деструкции}

Остановимся теперь на ключевой научной работе С. Н. Шпильрейн, отражающей ее взгляды на природу деструкции [10]. 
Для понимания этой статьи важно отметить, что С. Н. Шпильрейн в ней сознательно отказывается от постулатов классической психологии личности, в центр которой помещено сознательное Я (Эго). В западной логоцентрической традиции за Эго пожизненно закреплена прерогатива познавать, конструировать и оценивать мир. Однако, согласно учению С. Н. Шпильрейн, деструкция представляет собой феномен другого порядка и уровня, который несводим к процессам и состояниям Эго-сознания и может быть надлежащим образом исследован лишь в более укрупненном надличностном масштабе. Деструкция, утверждает С. Н. Шпильрейн, соразмерна самой тотальности жизни и, в общем-то, безразлична по отношению к отдельному индивиду с его здравым смыслом, стремлением к удовольствию или волей к власти. Деструктивные процессы, которые в индивидуальной системе оценок представляются едва ли не абсолютным «злом», оказываются важнейшими эволюционными факторами «на службе рода».

В свете психоаналитической историографии Сабина Николаевна Шпильрейн предстает, прежде всего, как предтеча Зигмунда Фрейда: согласно распространенной точке зрения, то, что ей удалось интуитивно и недостаточно ясно выразить в упомянутой статье, позднее переосмыслил и четко сформулировал отец-основатель психоанализа, разрабатывая собственную, довольно спорную, концепцию влечения к смерти. Иными словами, статья С. Н. Шпильрейн - лишь сырая заготовка, предварительный эскизный вариант основных психоаналитических постулатов, касающихся проблемы первичных влечений. Однако сопоставление воззрений 3. Фрейда и его ростовской ученицы позволяет выявить ряд существенных теоретических расхождений, причем столь глубоких, что, на наш взгляд, допустимо говорить о подходе С. Н. Шпильрейн как о плодотворной научной альтернативе классическому фрейдовскому учению.

Обратимся к хрестоматийной работе 3. Фрейда «По ту сторону принципа удовольствия» [9]. В ней 3. Фрейд пишет о консервативной природе Либидо о том, что энергия наших инстинктов, подчиняясь фундаментальной закономерности психического - принципу удовольствия, устремляет нас к разрядке напряженности и достижению удовлетворения наиболее привычными, проторенными путями. Происходит это помимо сознательной воли индивидуума, автоматически. При этом главная биологическая цель, консолидирующая все силы бессознательной части нашего «психического аппарата» - «удерживать наличное количество возбуждения на возможно более низком или, по меньшей мере, постоянном уровне» [9, с. 383]. Как писал 3. Фрейд, «принцип удовольствия выводится из принципа константности» [9, с. 383]. Наиболее полно этот принцип реализуется в сфере сексуальных влечений.

Присущие каждому первичные побуждения к удовольствию в повседневной 
жизни оттесняются требованиями социальной действительности, блокируются в силу действия таких факторов, как нормы морали, культурные запреты, установки и императивы, которые служат преградами для непосредственного удовлетворения и разрядки импульсов либидо. Социальная жизнь вынуждает субъекта согласовывать внутренние импульсы и побуждения с социальными обстоятельствами их реализации. Принцип реальности, постулированный 3. Фрейдом наряду с принципом удовольствия, предполагает периодическую отсрочку удовольствия: в социуме оно достигается трудным, окольным путем уступок и компромиссов. Именно стремлением к самосохранению в репрессивной социальной среде объясняется то обстоятельство, что индивиду приходится идти к удовлетворению базисных потребностей извилистыми тропами культуры и цивилизации; каждый на этом пути подобен гомеровскому Одиссею, который возвращаясь на Итаку, встретил множество мифических препятствий. Культура, как следует из теории 3. Фрейда, обеспечить полноту биологического удовлетворения не способна, поэтому она предлагает индивидууму лишь эрзац, суррогат утраченной «радости жизни», зыбкую химеру потерянного рая. С этим связана особая неудовлетворенность, которую 3. Фрейд обозначил как «недовольство культурой». В любой культуре заложен элемент подавления, вынужденного неудовольствия и неполноты удовлетворения, что стимулирует бесконечный поиск новых, замещенных и сублимированных форм наслаждения, служит залогом и источником всего разнообразия культурной жизни.

Таким образом, становление личности, дифференциация индивидуальной психики и общее усложнение душевной жизни, согласно теории 3. Фрейда, определяются столкновением сознательного Я со сложной и противоречивой социальной средой, ограничивающей исконные (консервативные) стремления к удовольствию, внутреннему равновесию и покою.

Вопреки сложившемуся убеждению, что все живое стремится к изменению и развитию, 3. Фрейд констатирует «консервативную природу живущего». Он определяет влечение как «наличное в живом организме стремление к восстановлению какого-либо прежнего состояния», как «выражение косности в органической жизни» [9, с. 404], и даже утверждает, что в конечном итоге «целью всякой жизни является смерть», поскольку «неживое было раньше, чем живое» [9, с. 405]. Иными словами, источник развития индивида обнаруживается не в глубинах психического, где зарождаются влечения, но в сфере взаимодействий с окружающей средой. «Если, - пишет 3. Фрейд, - все органические влечения консервативны, приобретены исторически и направлены к регрессу, к восстановлению прежних состояний, то мы должны все последствия органического развития отнести за счет внешних, мешающих и отклоняющих влияний» [9, с. 405]. 
Постулируя заложенную в индивидуальном Я тенденцию возврата к неорганическому состоянию как стремление, погрузившись в покой неживой материи, окончательно избавиться от любого внутреннего напряжения и внешнего раздражения, 3. Фрейд предлагает нам предельно дуалистическую картину психической жизни. Он противопоставляет влечения Я (но не к самосохранению, а как раз наоборот, к саморазрушению, к смерти) и влечения рода, направленные на созидание и приумножение жизни (сексуальность или, в более поздней редакции, влечение к жизни).

В упомянутой выше работе С. Н. Шпильрейн природа и судьба первичных влечений представлены в иной перспективе. Почти за десять лет до проведенной 3. Фрейдом ревизии С. Н. Шпильрейн ставит вопрос, имеющий для глубинной психологии первостепенное значение: нет ли в нас сил и влечений, которые приводят в движение нашу психическую субстанцию, не беспокоясь при этом о благе или вреде для Эго? Отвечая на этот вопрос, она высказывает мнение, «что душевным Я руководят побуждения, лежащие еще глубже (чем область удовольствия/неудовольствия. - Ф. Ф.) и совсем не заботящиеся о реакции нашего чувства на поставленные ими требования» [10, с. 212]. «Глубина нашей души, - читаем у С. Шпильрейн, - не знает никакого Я, но лишь его суммирование в «Мы» или в настоящее Я, выступающее как объект и подчиненное другим подобным объектам» [10, с. 213]. Этот пассаж перекликается с более поздними по времени рассуждениями К. Г. Юнга о коллективном бессознательном как об объективном психическом, т. е. как о той сфере душевной жизни, в которой индивидуальное Я оказывается мишенью воздействующих на него надличностных факторов (архетипов), или дословно «объектом всех Субъектов» [14]. Впрочем, предвосхищая идеи К. Юнга, С. Шпильрейн остается во фрейдистском проблемном поле. Она фокусирует свое исследовательское внимание преимущественно на инстинктивной сфере и стремится прояснить глубинную динамику человеческих побуждений, тогда как К. Юнг ставил перед собой несколько иную задачу. Он пытался выявить базовые принципы структурной организации индивидуального и коллективного опыта, установить, как структурируются наши представления, образы, убеждения, как психическое приходит к узнаванию и пониманию самого себя в архетипе, этом «автопортрете инстинкта». Воззрения К. Юнга и С. Шпильрейн выступают как взаимодополняющие научные идеи о структуре и динамике безличного (родового или коллективного) бессознательного. Не была ли работа С. Шпильрейн исторически первой попыткой примирить противоречия теоретических подходов 3. Фрейда и К. Г. Юнга в тот период, когда они ее только назревали и не были в полном объеме манифестированы?

У С. Н. Шпильрейн не только источником движущих сил поведения и развития индивида, но и активным, деятельным субъектом выступает 
т. н. «родовая душа» (понятийный конструкт, предвосхищающий коллективное бессознательное К. Юнга). Активность родовой души может быть разрушительной для индивида и при этом созидательной, конструктивной для рода.

Сабина Шпильрейн одной из первых в западной психологии осуществила «релятивизацию Эго» или, пользуясь выражением Ж. Лакана, «ниспровержение Субъекта», и предложила нам релятивистский взгляд на явление деструкции. Она показала, что значение феномена деструкции не является исключительно негативным, но изменяется в зависимости от выбранной исследователем «системы отсчета».

Рассматривая случаи dementia praecox (шизофрении) с их характерной символикой, С. Шпильрейн приходит к заключению, что душевная жизнь психотических пациентов определяется борьбой между двумя антагонистическими стремлениями - «Я-души» и «родовой души». Психопатология в заостренной и гипертрофированной форме показывает нам общую закономерность: здесь оказываются конфликтующими две основные тенденции психического функционирования как такового. Я-душа стремится к сохранению индивида в его актуальном дифференцированном состоянии, в котором превалируют Я-отношения и Я-представления. Именно с устойчивостью Я, сохранением дифференцированных психических содержаний и с возможностью самоутверждения связывается у С. Шпильрейн переживание удовольствия (а не со снижением уровня возбуждения, как у 3. Фрейда). В то же время, «душа рода» характеризуется тенденцией к ассимиляции, растворению индивидуальных представлений в безлично типичных, родовых, к замене дифференцированного Я-сознания «унаследованными и всеобщими формами мышления». Эго противится такой аннигиляции индивидуально-специфичного, что и выражается в чувстве неудовольствия. Иными словами, душевная жизнь есть борьба или, точнее, диалектика единичного и всеобщего, и пациент-психотик переживает эту борьбу наиболее болезненно и обостренно.

Динамика душевной жизни, полагает С. Н. Шпильрейн, выражается в чередовании двух основных тенденций: 1) дифференциации новых, индивидуально специфичных представлений из более древних, общечеловеческих; 2) ассимиляции, растворении индивидуального в типичном, общезначимом, родовом.

Все индивидуальное и новое проистекает из родовых источников, вычленяется из древнего коллективного опыта, который служит исходным материалом. С другой стороны, чтобы индивидуально своеобразное содержание было понято, воспринято и стало достоянием многих, оно должно быть преобразовано согласно более общей, универсальной схеме. При этом нечто уникальное и неизреченное словно растворяется - утрачивается, чтобы возникнуть вновь, в небывалых комбинациях, следуя бесконечному 
круговороту. Деструкция здесь означает не только разрушение, но и переструктурирование: борьба индивидуальной души и души рода - не есть жизнеотрицание, это непрерывное становление, развитие.

Таким образом, одним из аспектов деструкции выступает дифференциация. В понимании С. Н. Шпильрейн, - это вычленение индивидуальных представлений (или Эго-представлений) из системы представлений коллективных, рождение индивидуума из лона «родовой души», вычленение Я из коллективного «Мы». Индивид определяется как dividuum, отколовшийся, отделившийся от единства рода, лишенный целостности, значимый в своей отдельности и отличии от других. Фактически деструкция у С. Шпильрейн предстает в качестве основного механизма отделения сознания от недифференцированной коллективной психики, и вместе с тем как возвратное движение к первоистокам, как растворение Я в «Мы». На индивидуальном уровне деструкция означает как дифференциацию, так и аннигиляцию.

Индивидуальные представления формируются посредством разрушения/ расщепления родовых синкретов, тогда как понимание между субъектами рождается из деструкции индивидуально-специфичных, невыразимых в слове и уникальных психических содержаний. В языке происходит деструкция неизреченного и сокровенного. «Единство общения и обобщения» в слове достигается посредством разрушения уникально-личностного, не поддающегося унификации и вербализации. Эта идея находит отражение в классической русской поэзии: «Но душу можно ль рассказать?» (М. Ю. Лермонтов); «Мысль изреченная есть ложь» (Ф. И. Тютчев).

Отделение от родовой души оборачивается одиночеством и невозможностью выразить значимые для субъекта, исключительные и ценные в своей единичности переживания; возвращение в сферу разделяемого, коллективного, всеобщего дается ценой утраты невыразимого личностного смысла, его растворения в универсальном.

В то же время, деструкция устоявшейся системы Я-представлений и возврат к истокам могут обернуться вторым рождением, стать значимым этапом личностного развития, предпосылкой интеграции на новом уровне самосознания и психологической зрелости. За ассимиляцией, растворением уникального, неизреченно-личного следует его возрождение в новой, ранее неизвестной форме. Подтверждением этому служит неоднократно отмечавшееся воздействие на личность сакральных ритуалов, отражающих универсальную символику «смерти-возрождения».

Итак, цикличная смена фаз дифференциации и ассимиляции представлений является своеобразным законом психической жизни. Все индивидуальное и новое проистекает из коллективных, родовых источников, вычленяется из древнего, недифференцированного состояния - души рода. Но для того, 
чтобы индивидуально своеобразное содержание было понято, воспринято и стало достоянием многих, оно должно быть преобразовано согласно более общей, универсальной матрице. Как пишет С. Н. Шпильрейн, «ассимиляция приводит к тому, что из единства, имеющего значение для Я, рождается единство, значимое для “Мы”» [10, с. 214].

Переводя вышеизложенные идеи на язык теории влечений, С. Шпильрейн предлагает различать два основных инстинкта: инстинкт самосохранения и инстинкт сохранения вида. Первый из них прост по структуре и консервативен, т. к. направлен на сохранение индивида в уже имеющемся наличном состоянии. Второй преследует цель сохранения рода путем постоянных изменений и новообразований, независимо от эгоистических желаний индивида и его стремления к устойчивости. Инстинкт сохранения рода имеет сложную двухкомпонентную структуру; в нем эротическое влечение неотделимо от деструкции. Таким образом, этот инстинкт амбивалентен по своей природе, т. е. включает в себя как отрицательные, так и положительные (с точки зрения Эго) компоненты. Биологический смысл и предназначение деструктивных импульсов, согласно С. Н. Шпильрейн, - уничтожение старого состояния ради возникновения нового, разрушение, обеспечивающее трансформацию, «воскрешение» индивида в новой форме. Любое развитие осуществляется путем дестабилизации и деструкции. А поскольку род человеческий может сохраниться, только постоянно развиваясь и эволюционируя, разрушение есть необходимый элемент жизни, как бы печально это ни воспринималось нами в контексте индивидуальной биографии. Деструкция, таким образом, выступает в качестве основного креативного эволюционного принципа как центральный фактор «творческой эволюции» всего живого.

Очевидно противоречие между таким диалектическим пониманием либидо, как источника индивидуального развития и трансформации, и предложенным 3. Фрейдом определением влечения как «выражения косности в органической жизни». Цель первичных побуждений, согласно С. Н. Шпильрейн, это постоянное изменение и формообразование, по 3. Фрейду же - регресс, возврат к прежде бывшим состояниям. У С. Н. Шпильрейн влечения рода - психологический аналог бергсоновского élan vital, фактор творческой эволюции живого; у 3. Фрейда они изначально консервативны. В первом случае, деструкция - залог нового рождения, во втором - аннигиляция, «успокоение» живого путем его уравнивания с неорганической материей. И 3. Фрейд, и С. Шпильрейн опираются на биологические факты, однако первый верен механистическому детерминизму и предлагает нам модель "автоматического бессознательного», в которой психический аппарат представлен как биосоциальный механизм, подобно более ранним новоевропейским представлениям о телесной машине. В теории С. Н. Шпильрейн 
мы обнаруживаем «бессознательное органическое» - сопричастное самой жизни, творческое и созидающее через разрушение.

Можно прийти к заключению, что С. Н. Шпильрейн облекла в психологическую форму одну из древнейших идей, принципиально важных для понимания культурной и духовной истории человечества. Эта идея обнаруживается у самых истоков как мифологического (извечная мифологема «смерти-возрождения»), так и диалектического мышления. У отца диалектики Гераклита она представлена в виде известного парадоксального афоризма: «Война - мать всех вещей». Сабина Николаевна сформулировала ту же мысль в качестве универсального принципа организации и развития живой материи, формирования Я-сознания (индивидуальной души) и ассимиляции неизреченно-субъективного в коллективной системе репрезентации (т. е., согласно ее терминологии, в родовой душе).

Что препятствует пониманию главной работы С. Шпильрейн, почему даже 3. Фрейд, безусловно, ценивший ее, признал эту статью недостаточно ясной?

Ознакомление с текстом позволяет заключить, что статья С. Н. Шпильрейн «деструктивна» (или, выражаясь постмодернистским языком, деконструктивна) по отношению к логоцентрической традиции, доминировавшей в психоаналитическом сообществе начала XX в.

В статье действительно нарушен принцип западного логоцентризма, строгого рационального изложения, постулирования и обоснования, что неизбежно навлекает обвинения в недостаточной интеллектуальной дисциплине автора и бессистемности учения, едва ли могущего претендовать на статус самостоятельной целостной теории. Здесь в единой плоскости анализа как равноценные доказательства авторских тезисов представлены научные данные, клинические наблюдения и мифопоэтические иносказания, метафоричность литературных, теологических и мифологических источников равноправно уживается с неоспоримостью биологического факта. При таком «смешении языков» происходит, с одной стороны, характерная для постмодернистского дискурса релятивизация человеческого знания как такового, а с другой - абсолютизация принципа деструкции, который провозглашается универсальным, своего рода «законом жизни», трансцендентным по отношению к конкретным языковым играм с их частными правилами. Слияние (интеграция) двух половых клеток, дающее начало новому организму, вместе с тем означает деструкцию - их взаимное уничтожение в качестве самостоятельных единиц жизни. Это свидетельство биологической науки приобретает в изложении С. Н. Шпильрейн поистине сакральное звучание, как будто автор обращается к первоистокам основных мифов, извечно волнующих человечество. Изложение авторских тезисов осуществляется по спирали, и вскоре выясняется: «наверху то же самое, что и внизу». 
Таким образом, снимаются бинарные оппозиции «жизни - смерти», «возвышенного - низменного», «верха - низа». В высших сферах ментальности и духа торжествуют те же извечные законы, что и на уровне взаимодействия половых клеток: интеграция осуществляется путем деструкции, новое рождается ценой разрушения старого.

Итак, С. Н. Шпильрейн опережает свое время не только в содержании статьи, которое все же укладывается в рамки модернистского мировоззрения, вызывая ассоциации с метафорическими текстами Ф. Ницше, но и в способе изложения, в стиле письма. Она соединяет в своем тексте научное, философское и мифопоэтическое, сводя на нет привычное противопоставление и размежевание этих форм познания.

В завершение еще раз отметим, что тема деструкции - это не только ключевой концепт учения С. Н. Шпильрейн, но и своеобразный лейтмотив ее жизни. Крайне болезненная деструктивная атмосфера в семье и смерть младшей сестры Эмилии способствовали не только развитию у Сабины Николаевны психического заболевания, но также раннему становлению самосознания и проявлению незаурядной одаренности, о чем свидетельствуют ее детские дневники. Болезнь, о которой так много написано, не только привела девятнадцатилетнюю девушку из Ростова-на-Дону в крупнейшую психиатрическую клинику Европы, но и стала предпосылкой отделения от патогенной семейной системы, самопознания и дальнейшего самоопределения. Из деструкции юношеского кризиса родилось более дифференцированное сознание и новая профессиональная идентичность - вчерашняя пациентка стала врачом. Позднее сложные деструктивные отношения с Карлом Юнгом позволили Сабине Шпильрейн осмыслить и выразить важнейшие для психоаналитической теории и практики идеи. В темной истории с «малышкой» Сабиной можно усматривать предпосылки разрыва между 3. Фрейдом и К. Юнгом и раскола психоаналитического движения; вместе с тем, в трудах самой С. Н. Шпильрейн мы обнаруживаем попытку интеграции теоретических воззрений этих двух выдающихся ученых. Символический сын Зигфрид, о котором Сабина Николаевна мечтала в период наиболее сильных чувств к К. Юнгу, был призван объединить в себе все лучшее, что есть в арийской и семитской расах. Вместо него она подарила научному миру статью, в которой оказались максимально сближены и увязаны позиции ее размежевавшихся учителей.

За десять лет плодотворной работы Сабина Николаевна Шпильрейн внесла существенный вклад в развитие психоанализа, а также детской психологии $[6,11,19,21]$, предвосхитив более поздние открытия Зигмунда Фрейда, Анны Фрейд, Мелани Кляйн, Жана Пиаже, Дональда Винникотта.

В 1923 г. Сабина Шпильрейн приняла роковое для ее последующей судьбы решение вернуться в СССР - решение, поддержанное 3. Фрейдом, который 
таким образом невольно сыграл деструктивную роль в ее жизненной драме. Жизнь Сабины Николаевны вплоть до трагической гибели - это период забвения и тяжелых утрат. Однако и переезд в Ростов-на-Дону и трагическая гибель в Змиевской балке, в свете ее учения, могут интерпретироваться как символическое возвращение к истокам, окончательное воссоединение личной судьбы с Судьбой родного города и народа. История жизни Сабины Николаевны показывает, как деструкция и интеграция парадоксально переплетаются в пределах индивидуальной биографии.

\section{Литература}

1. Ванинг А. ван. Работы одного из пионеров психоанализа - Сабины Шпильрейн // Вопросы психологии. - 1995. - № 6. - С. 66-78.

2. Мовшович E. В. Очерки истории евреев на Дону. - Ростов н/Д: Книга, 2011. - 336 C.

3. Овчаренко В. И. Сабина Шпильрейн: под знаком деструкции // Логос. 1994. - № 5. - С. 239-256.

4. Овчаренко В. И. Судьба Сабины Шпильрейн // Российский психоаналитический вестник. - 1992. - № 2. - С. 64-69.

5. Рихебехер С. Сабина Шпильрейн: «почти жестокая любовь к науке». Биография. - Ростов н/Д: Феникс, 2007. - 413 с.

6. Сабина Шпильрейн (1885-1942). Материалы к биобиблиографии / Сост. и ред. С. Ф. Сироткин. - М.: Русское психоаналитическое общество; Ижевск: ИД «ЕRGO», 2006. - 84 с.

7. Сабина Шпильрейн: над временем и судьбой: Сб. статей. - Ростов н/Д: Минитайп, 2004. - С. 256.

8. Филатов Ф. Р. Две альтернативные теории влечений в психоанализе // Сумма психоанализа. Антология / Под ред. В. И. Овчаренко. Toм 12 // URL: http://lib100.com/book/psychoanalis/amount_psy_ 12 /_\%D0\%A 1\%D 1\%83\%D0\%BC\%D0\%BC\%D0\%B0\%20\%D0\%BF \%D $1 \% 81 \%$ D 0\%B 8\%D 1 \% 85\%D0\%BE\%D0\%B0\%D0\%BD\%D0\%B0\% D0\%BB\%D0\%B8\%D0\%B7\%D0\%B0.\%20\%D0\%90\%D0\%BD\%D1\%82\% D 0 \% BE \% D 0 \% B B \% D 0 \% BE \% D 0 \% B 3 \% D 0 \% B 8 \% D $1 \% 8$ F. \% 20 $\% \mathrm{D} 0 \% \mathrm{~A} 2 \% \mathrm{D0} \% \mathrm{BE} \% \mathrm{D} 0 \% \mathrm{BC} \% 20$ 12.pdf

9. Фрейд 3. По ту сторону принципа удовольствия // Фрейд 3. Психология бессознательного. - М.: Просвещение, 1990. - С. 382-424.

10. Шпильрейн С. Деструкция как причина становления. - М.: Логос, 1994. № 5. - С. 207-239.

11. Шпильрейн С. Психоаналитические труды / Пер. с англ., нем. и франц. под науч. ред. С. Ф. Сироткина, Е. С. Морозовой. - Ижевск: ИД «ERGO», 2008. - 466 c. 
12. Штефран И. Сабина Шпильрейн (1885-1942) - «предмет обмена» между Юнгом и Фрейдом // Вестник Психоанализа. - 2000. - № 2.

13. Эткинд А. М. Эрос невозможного: История психоанализа в России. - СПб., 1993; М., 1994. - С. 159-212.

14. Юнг К. Г. Об архетипах коллективного бессознательного // Юнг К. Г. Архетип и Символ. - М.: Ренессанс, 1991. - С. 95-129.

15. Berch B. Sex versus Survival: The Life and Ideas of Sabina Spielrein. - New York: Jewish Book Council, 2015.

16. Carotenuto A. A Secret Symmetry. Sabina Spielrein between Jung and Freud. New York: Pantheon Books, 1982.

17. Cooper-White P. The power that beautifies and destroys. Sabina Spielrein and "Destruction as the Cause of Coming into Being" // Pastoral Psychology. 2015. - 64. - pp. 259-278.

18. Etkind A. Eros of the Impossible: The History of Psychoanalysis in Russia. Boulder, CO: Westview Press, 1997. - P. 172.

19. Sabina Spielrein: Forgotten Pioneer of Psychoanalysis / Ed. by C. Covington and B. Wharton. - New York, 2003. - pp. 287-305.

20. Spielrein S. Die Destruktion als Ursache des Werdens // Jahrbuch für psychoanalytische und psychopathologische Forschungen. - 1912. - 4. - pp. 465-503.

21. Waning A. van. The works of pioneering psychoanalyst Sabina Spielrein // International Review of Psychoanalysis. - 1992. - 19. - pp. 399-413. 